\title{
DESENVOLVIMENTO DE JUVENIS RECENTES DA Panulirus laevicauda, ALIMENTADAS COM MOLUSCOS E DIETA PELETIZADA ${ }^{1}$
}

\author{
Carlos Henrique dos Anjos dos Santos ${ }^{1}$, Jullyermes Araújo Lourenço² E Marco Antonio Igarashi ${ }^{3}$
}

1. Laboratório de Ecofisiologia e Evolução Molecular, Instituto Nacional de Pesquisas da Amazônia. Doutorando em Genética, Conservação e Biologia Evolutiva, bolsista do CNPq. E-mail: carloshenrique@inpa.gov.br

2. Departamento de Engenharia de Pesca. Centro de Tecnologia em Aquicultura - UFCE. Doutorando em Engenharia de Pesca, bolsista da CAPES 3. Departamento de Engenharia de Pesca, Centro de Tecnologia em Aquicultura, UFCE, bolsista de Produtividade do CNPq.

\section{RESUMO}

Realizou-se este experimento no Centro de Tecnologia em Aquicultura da Universidade Federal do Ceará no período de 14 de março a 14 de julho de 2006. O objetivo foi comparar o desenvolvimento de juvenis recentes da Panulirus laevicauda, alimentadas com moluscos (Perna perna e Mytella falcata) e dieta peletizada. Desenvolveram-se três tratamentos (TA - P. perna, TB - M. falcata e TC - dieta peletizada) com quatro repetições, distribuídos em delineamento inteiramente casualizado. A densidade de estocagem foi de um indivíduo por recipiente. A alimentação ofertada foi de $10 \%$ da biomassa. Na manutenção do experimento, mediram-se o $\mathrm{pH}$, a temperatura e a salinidade e realizaram-se biometrias mensais. Ampliaram-se os seguintes testes estatísticos: Kolmogorov-Smirnov, teste " $t$ " de Student, ANOVA e o teste do qui-quadrado. Os parâmetros físico-químicos não diferiram estatisticamente entre si $(P>0,05)$. As taxas em ganhos, incrementos, números de mudas, frequências de mudas e taxas de sobrevivência não apresentaram diferenças estatísticas entre os tratamentos $(P$ $>0,05)$. A P. laevicauda tem ótima aceitação de uma dieta peletizada na sua alimentação. Já outras espécies de lagostas não se alimentam de tais dietas.

PALAVRAS-CHAVES: Desenvolvimento, Mytella falcata, Panulirus laevicauda, Perna perna, ração comercial.

ABSTRACT

\section{DEVELOPMENT OF EARLY JUVENILES OF Panulirus laevicauda, FED ON MOLLUSCS AND PELLETED DIET}

This experiment was carried out at the Technology Center of Aquaculture, Federal University of Ceara during the period of March $14^{\text {th }}, 2006$ to July $14^{\text {th }}, 2006$. The objective of this study was to compare the growth of early juveniles of Panulirus laevicauda, fed on molluscs (Perna perna and Mytella falcata) and pelleted feed. The experiments were delineated and conducted using completely randomized distributions. Three treatments (TA $-P$. perna, $\mathrm{TB}-M$. falcata and $\mathrm{TC}-$ pellet feed) were repeated 4 times. Initial density used was one individual per container. The feed rate was $10 \%$ of the individual biomass. The chemical and physical parameters of the experimental water $(\mathrm{pH}$, temperature and salinity) were measured daily and the juveniles were measured verifying cephalotorax and total length and weighed at each 30 days of culture. For the statistical tests Analysis with Kolmogorov-Smirnov the Student Test (chemical and physical parameters), Analysis of Variance (ANOVA) and test CHI-SQUARE, were used. In this work chemical and physical parameters did not show differences among the treatments $(P>0.05)$. At the end of the experiment, growth rate, number and frequency of molts per individual, and survival rate did not show statistical differences $(P>0.05)$. $P$. laevicauda has a good acceptance of pelleted feed but other species of lobster did not feed of this type of diets.

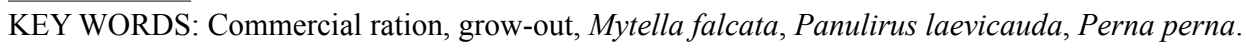

\section{INTRODUÇÃO}

A lagosta verde, Panulirus laevicauda, ocorre na região tropical com área de distribuição desde o Caribe,
Cuba até o Estado da Bahia no Brasil. No entanto, essa espécie é capturada com maior intensidade na costa do Estado do Ceará, tendo uma participação significativa nas exportações de lagostas. 
Nos últimos anos, vem-se verificando um forte declínio nas pescarias de lagostas no Brasil, e a pesca predatória tem contribuído para a redução e provável esgotamento dos estoques naturais (SANTOS, 2000) deste crustáceo. Segundo IGARASHI \& MAGALHÃES NETO (2001), a superexploração deste recurso tem ocasionado um crescente aumento do desemprego no setor lagosteiro nacional.

Para alguns pesquisadores, uma das formas recomendadas para reverter esse quadro seria expandir a produção desse crustáceo por meio da aquicultura (KITTAKA \& BOOTH, 2000). No entanto, existe um grande entrave para o cultivo comercial da lagosta, que é seu lento crescimento e um complexo período larval, principalmente das espécies de grande interesse para aquicultura.

Dessa forma, enquanto a larvicultura não estiver viável comercialmente, os estudos sobre esses crustáceos serão destinados às coletas de puerulus e juvenis para a engorda em cativeiro até que se atinja o tamanho comercial (BOOTH \& KITTAKA, 2000).

As pesquisas realizadas no Brasil destacam a engorda de puerulus da lagosta vermelha $P$. argus (IGARASHI, 2000) e juvenis recentes da $P$. laevicauda (IGARASHI \& KOBAYASHI, 1997) até o tamanho comercial, bem como o acasalamento da lagosta verde em laboratório (IGARASHI \& SANTOS, 2000).

Contudo, alguns trabalhos vêm sendo realizados ao redor do mundo para que se viabilize o cultivo comercial da lagosta. E um dos principais focos abordados nesses estudos são as dietas ofertadas às lagostas (KOBAYASHI, 1998; CREAR et al., 2000; ARAGÃO, 2005; SMITH et al., 2005; BARCLAY et al., 2006; SANTOS, 2006). Porém, o sucesso do cultivo comercial da lagosta está parcialmente dependente da formulação de uma dieta economicamente viável e eficiente (KOBAYASHI, 1998).

A utilização de dietas artificiais é mais eficiente do que de alimentos naturais, em virtude do menor problema de coleta, da variação sazonal na qualidade, do armazenamento e manipulação (KITTAKA, 2000; KITTAKA \& BOOTH, 2000). Entretanto, as dietas artificiais ofertadas às lagostas devem atender às necessidades e qualidades nutricionais do animal.

Sabe-se, porém, que algumas espécies de lagostas não aceitam dietas artificiais em sua alimentação, como é o caso da $P$. argus (DIAZ-IGLASIAS et al.,
1991; LELLIS, 1992; CONCEIÇÃO, 1993). Já as espécies $P$. laevicauda (SANTOS et al., 2003; SANTOS, 2006), P. cygnus (GLENCROSS et al., 2001), P. ornatus (SMITH et al., 2003, SMITH et al,. 2005; BARCLAY et al., 2006), Jasus edwardsii (CREAR et al., 2000) e Homarus americanus (BOWSER \& ROSEMARK, 1981) aceitam tais tipos de alimento na sua alimentação.

Sendo assim, o presente trabalho teve como objetivo testar alternativas de alimentos para o desenvolvimento de juvenis da P. laevicauda em cativeiro.

\section{MATERIAL E MÉTODOS}

Este experimento foi realizado nas instalações do Centro de Tecnologia em Aquicultura (CTA) da Universidade Federal do Ceará (UFC), no período de 14 de março a 14 de julho de 2006, com duração de 122 dias.

Capturaram-se os juvenis da lagosta espinhosa P. laevicauda na costa de Fortaleza, Ceará, durante as marés baixas de sizígia. Após a coleta, os juvenis foram levados ao CTA e colocados em aquário de 100 L, para a aclimatação. Ao término desse processo, as lagostas permaneceram por mais duas semanas nos recipientes, para que se adaptassem às novas condições de ambiente.

Para este experimento utilizaram-se caixas de polietileno com volume útil de $30 \mathrm{~L}$, colocando-se dentro dessas caixas recipientes plásticos perfurados com volume de $2 \mathrm{~L}$. Manteve-se a oxigenação da água por meio de pedras porosas ligadas a um compressor de ar. O fotoperíodo utilizado foi de doze horas luz (lâmpadas fluorescentes de 40 watts) e doze horas de escuro.

Utilizou-se o delineamento experimental inteiramente casualizado, distribuídos em três tratamentos (TA - Perna perna, TB - Mytella falcata e TC - ração peletizada para camarão com $40 \% \mathrm{~PB}$ ) com quatro repetições. Os juvenis foram cultivados isoladamente, totalizando doze exemplares da lagosta verde.

Realizou-se o manejo do módulo de cultivo diariamente, com a sifonagem dos restos de alimentos não consumidos e fezes, renovação diária da água em torno de $10 \%$ a $30 \%$ do volume total. Coletou-se a água utilizada na reposição semanalmente na Praia do Icaraí no município de Caucaia, Ceará. A alimentação foi fornecida com base em $10 \%$ da biomassa. 
Os parâmetros da qualidade da água observados diariamente foram temperatura, $\mathrm{pH}$ e salinidade. Não se efetuou a medida da amônia total, em virtude das constantes renovações de água. A temperatura foi monitorada com termômetro digital com acuidade de $0,1^{\circ} \mathrm{C}, \mathrm{pH}$ com peagâmetro de acuidade de 0,01 e a salinidade por um refratômetro com acuidade de $1 \%$, respectivamente.

As biometrias foram realizadas mensalmente, sendo o peso determinado utilizando-se uma balança com acuidade de $0,001 \mathrm{~g}$. Já o comprimento total foi medido com um paquímetro com acuidade de $0,05 \mathrm{~mm}$. Verificaram-se a mortalidade e o número de muda diariamente, a partir da observação direta das unidades experimentais, determinando, assim, a sobrevivência e o número de muda aparente. Também se observaram para este experimento as taxas de incrementos diários e os incrementos finais em peso e comprimento total das lagostas.

As análises bromatológicas dos alimentos ofertadas às lagostas foram determinadas segundo o INSTITUTO ADOLFO LUTZ (1985) e a AOAC (1990) (Tabela 1). Em relação aos valores nutricionais da dieta peletizada, obtiveram-se os dados por meio do fabricante (Tabela 1).

TABELA 1. Informações nutricionais das dietas naturais (moluscos Perna perna e Mytella falcata) e da dieta peletizada

\begin{tabular}{|c|c|c|}
\hline \multicolumn{3}{|c|}{ Alimentos } \\
\hline & Perna perna & Mytella falcata \\
\hline Composição & \multicolumn{2}{|c|}{ Níveis de garantia (\%) } \\
\hline Umidade (\%) & 82,18 & 73,79 \\
\hline Proteína total (\%) & 10,43 & 13,36 \\
\hline Lipídeo total (\%) & 2,20 & 1,55 \\
\hline Carboidratos (\%) & 4,26 & 2,27 \\
\hline Cinzas $(\%)$ & 0,93 & 4,03 \\
\hline \multicolumn{3}{|c|}{ Dieta peletizada* } \\
\hline Umidade (máxima) & \multicolumn{2}{|c|}{13,00} \\
\hline Proteína bruta (mínima) & \multicolumn{2}{|c|}{40,00} \\
\hline Extrato etéreo (mínimo) & \multicolumn{2}{|c|}{8,50} \\
\hline Matéria fibrosa (máxima) & \multicolumn{2}{|c|}{7,00} \\
\hline Matéria mineral (máxima) & \multicolumn{2}{|c|}{14,00} \\
\hline Cálcio (máximo) & \multicolumn{2}{|c|}{4,00} \\
\hline Fósforo (mínimo) & \multicolumn{2}{|c|}{1,00} \\
\hline
\end{tabular}

*Enriquecimento por $\mathrm{kg}$ do produto: ácido fólico 9,60 mg, ácido pantotênico $60,00 \mathrm{mg}$, colina $10,00 \mathrm{mg}$, cobre $120,00 \mathrm{mg}$, cobalto $1,20 \mathrm{mg}$, inositol 120,00 mg, iodo 5,40 mg, selênio $0,24 \mathrm{mg}$, vitamina A 7.800,00 UI, vitamina B1 12,00 mg, vitamina B12 60,00 mcg, vitamina B2 23,00 $\mathrm{mg}$, vitamina B6 12,00 mg, vitamina C 240,00 mg, vitamina D3 1.8000,00 UI, vitamina E 120,00 mg, vitamina K3 4,80 mg, zinco 100,00 mg, biotina $1,20 \mathrm{mg}$, antioxidante $200,00 \mathrm{mg}$.
Procedeu-se às análises estatísticas dos parâmetros físico-químicos pelos testes de KolmogorovSmirnov e o teste t-Student. Já para as taxas de ganhos em peso e comprimento total, incrementos em peso e comprimento total, números de mudas e frequência de mudas, utilizou-se ANOVA unifatorial. Existindo diferença estatística significativa, fez-se uso do teste de Tukey. Na sobrevivência, realizou-se o teste do Quiquadrado (MENDES, 1999; AYRES et al., 2003). O nível de significância utilizando foi de $\alpha=0,05$.

\section{RESULTADOS E DISCUSSÃO}

Neste experimento, a temperatura, o $\mathrm{pH}$ e a salinidade da água do cultivo variaram de $24,30^{\circ} \mathrm{C}$ a $28,00{ }^{\circ} \mathrm{C} ; 6,20$ a 7,90 e $36,00 \%$ a $42,00 \%$, para os tratamentos TA, TB e TC. Já as médias finais apresentaram os seguintes valores: $26,00 \pm 0,80{ }^{\circ} \mathrm{C} ; 7,30 \pm 0,20$ e 38,20 $\pm 2,00 \%$ para todos os tratamentos.

O teste de Komogorov-Smirnov mostrou que a temperatura, o $\mathrm{pH}$ e a salinidade atenderam à suposição da normalidade. Após isso, foi realizado o teste t-Student, que constatou não haver diferenças estatísticas significativas entre os tratamentos $(P>0,05)$ para as variáveis analisadas.

KOBAYASHI (1998) citou que em seu trabalho a temperatura média variou de $25,30^{\circ} \mathrm{C}$ a $25,70^{\circ} \mathrm{C}$ em um cultivo com a $P$. argus. BOOTH \& KITTAKA (2000) referiram que temperaturas abaixo de $15,60^{\circ} \mathrm{Ce}$ acima $\operatorname{dos} 32,20^{\circ} \mathrm{C}$ não são toleradas por muito tempo pelas lagostas, ocasionando mortalidade em massa desses indivíduos. Em relação ao $\mathrm{pH}$ da água do cultivo, ARAGÃO (2005) relatou variação em torno de 7,71 a 8,69, e pH médio de 8,01 para o cultivo de $P$. argus com diferentes dietas naturais. Segundo ESTEVES (1998), as condições fisiológicas dos organismos aquáticos poderão ser afetadas por diferenças no potencial hidrogenciônico na água do cultivo. WIEGAND (2005) mencionou que juvenis de $P$. argus se desenvolvem bem em salinidades variando de $30,00 \%$ a 40,00 \%o. Porém, de acordo com BOOTH \& KITTAKA (2000), os palinurídeos são indivíduos restritamente de águas oceânicas e próximas à costa. Já juvenis podem resistir por alguns dias a reduções graduais de salinidade até a faixa de $20,00 \%$.

Portanto, verificou-se que os resultados aqui encontrados no que concerne à temperatura e salinidade 
estão dentro das faixas recomendadas, porém o $\mathrm{pH}$ apresentou valores abaixo do encontrado para a água do mar $(8,00$ a 8,50$)$ (IGARASHI, 2007).

No que concerne às taxas de ganhos em pesos e comprimentos totais da $P$. laevicauda, a análise de variância mostrou que não existiu diferença estatística significativa entre os indivíduos alimentados com as dietas testadas $(P>0,05)$ (Figuras 1).

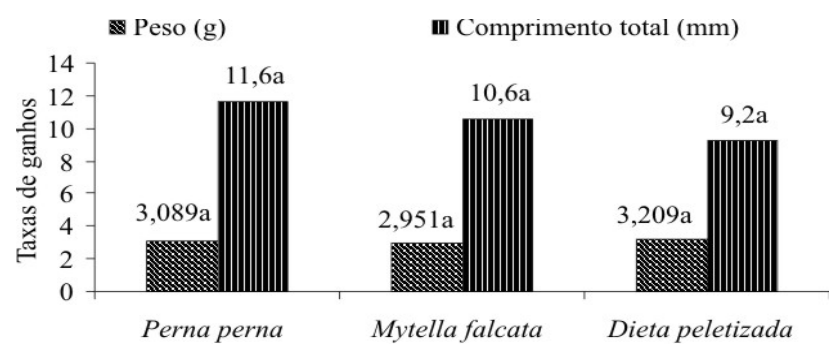

FIGURA 1. Taxas de ganhos em pesos (g) e comprimentos totais (mm) da lagosta espinhosa Panulirus laevicauda, durante os 122 dias de cultivo, alimentadas com os moluscos Perna perna, Mytella falcata e dieta peletizada, em laboratório. Letras iguais não diferem entre si estatisticamente $(P>0,05)$.

WIEGAND et al. (2006) utilizaram diferentes dietas na alimentação de juvenis recentes de $P$. argus com peso médio inicial de $1,670 \mathrm{~g}$ e obtiveram ao final do cultivo peso médio final variando de $3,854 \mathrm{~g}$ a 6,359 g. BARCLAY et al. (2006) cultivaram juvenis da espécie $P$. ornatus e obtiveram ao final de quatro meses ganho em peso variando de $1,71 \mathrm{~g}$ a 3,30 g, sendo que os indivíduos alimentados com dietas peletizadas apresentaram taxas de ganhos em pesos melhores do que os indivíduos alimentados com mexilhões frescos. CREAR et al. (2000) cultivaram juvenis de Jasus edwardsii e observaram que os indivíduos alimentados com $M$. edulis $(8,29 \pm 0,12 \mathrm{~g})$ apresentaram melhores ganhos em pesos do que os juvenis alimentados com ração comercial para camarão Penaeus monodon $(6,66$ $\pm 0,03 \mathrm{~g})$ e peixes triturados $(5,76 \pm 0,13 \mathrm{~g})$.

IGARASHI (2000) cultivou um juvenil recente de $P$. laevicauda de $1 \mathrm{~g}$ até o tamanho comercial $(11 \mathrm{~cm}$ de comprimento de cauda e $253 \mathrm{~g}$ de peso total), em aproximadamente 1,5 anos. Segundo BOOTH \& KITTAKA (2000), várias espécies de lagostas podem ser cultivadas até o tamanho comercial de $200 \mathrm{~g}$ a $300 \mathrm{~g}$, em apenas dois a três anos, sendo que algumas espécies podem ser cultivadas em um tempo mais curto.
Dessa forma, verificou-se que os resultados encontrados neste trabalho mostram valores para os ganhos em peso e comprimento total similares. Entretanto, os resultados estão dentro da faixa encontrada por BARCLAY et al. (2006), próximos da encontrada por WIEGAND et al. (2006), porém bem abaixo dos resultados verificados por CREAR et al. (2000).

Apesar disso, os resultados deste trabalho são animadores, se levado em consideração que se utilizou uma dieta peletizada na alimentação da lagosta $P$. laevicauda, já que um dos principais problemas para o cultivo em cativeiro da lagosta seria a aceitação, por parte desta, de uma dieta peletizada na sua alimentação.

Os dados sobre os incrementos em peso (\%) e comprimento total (\%) apresentaram valores bastante próximos nos tratamentos testados (Figura 2). Dessa forma, após a realização da ANOVA, verificou-se que não houve diferença estatística significativa nos incrementos, em relação às dietas ofertadas $(P>0,05)$.

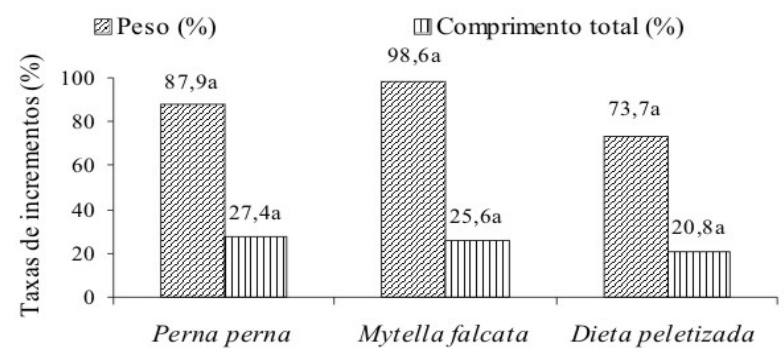

FIGURA 2. Taxas de incrementos em pesos (\%) e comprimentos totais (\%) da lagosta espinhosa Panulirus laevicauda, durante os 122 dias de cultivo, alimentadas com os moluscos Perna perna, Mytella falcata e dieta peletizada, em laboratório. Letras iguais não diferem entre si estatisticamente $(P>0,05)$.

ARAGÃO (2005) cultivou juvenis recentes de $P$. argus alimentados com diferentes dietas naturais e obteve, ao final do cultivo, variação de $221,7 \%$ a $527,8 \%$ para o incremento em comprimento total. KOBAYASHI (1998) mencionou que, em um cultivo com a mesma espécie, obteve ao final do ensaio variação de $55,24 \%$ a $89,96 \%$ para o incremento em comprimento do cefalotórax.

São raros na literatura científica dados sobre taxas de incrementos em lagostas, ainda que comuns 
para trabalhos com camarões marinhos. Contudo, sabe-se que as taxas de incrementos em comprimentos de lagostas e camarões são bem diferentes em seus resultados. Este fato é observado, pois os camarões realizaram mudas com maiores frequência do que as lagostas, que são crustáceos de crescimento lento, quando comparados com os camarões peneídeos.

Neste trabalho, constatou-se que o incremento relativo diário da biomassa não diferiu estatisticamente entre si $(P>0,05)$ (Figura 3).

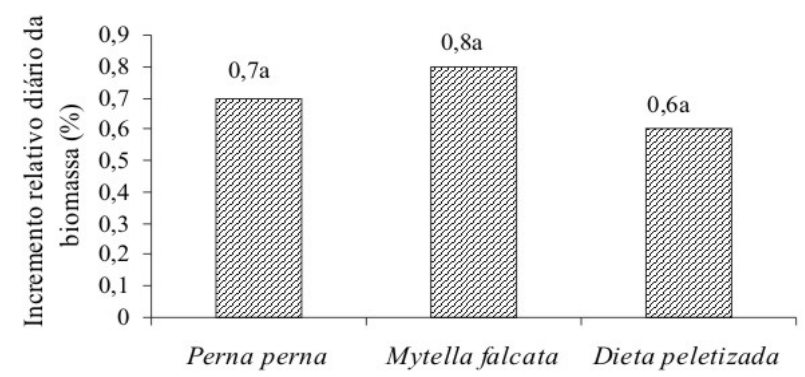

FIGURA 3. Taxas de incrementos relativos diários da biomassa (\%) da lagosta espinhosa Panulirus laevicauda, durante os 122 dias de cultivo, alimentadas com os moluscos Perna perna, Mytella falcata e dieta peletizada, em laboratório. Letras iguais não diferem entre si estatisticamente $(P>0,05)$.

CONCEIÇÃO (1993), em cultivo de $P$. argus no inverno e verão, constatou que no inverno as lagostas apresentaram incrementos relativos de 2,03\% (temperatura ambiente/agrupadas), $0,42 \%$ (temperatura elevada/agrupadas), 1,76\% (temperatura ambiente/isoladas) e $4,08 \%$ (temperaturas/isoladas), respectivamente. Porém, os indivíduos cultivados no verão apresentaram valores de $1,03 \%$ e $2,46 \%$ para indivíduos cultivados isoladamente e agrupados, respectivamente.

Desse pressuposto, conclui-se que os resultados encontrados neste trabalho foram superiores aos relatados por CONCEIÇÃO (1993) apenas para o período em que as lagostas foram cultivadas com temperaturas elevadas/ agrupadas e inferiores aos outros períodos avaliados. Dessa forma, trata-se de resultados que mostram que a lagosta P. laevicauda levaria mais tempo para atingir o tamanho comercial, caso sua taxa de incremento relativo diário de biomassa continue nesses patamares, necessitando-se, assim, de um tempo mais prolongado para o cultivo.

As lagostas alimentadas com P. perna, M. falcata e dieta peletizada apresentaram 9,8 e 9 números de mudas. No que concerne à frequência de muda, as lagostas tiveram um período de intermudas de 25 dias para as lagostas alimentadas com P. perna e 27 dias para os indivíduos alimentados com $M$. falcata e dieta peletizada, respectivamente. Esses dados finais mostraram que o número de mudas e a frequência de mudas não diferiram estatisticamente entre si $(P>$ $0,05)$, dado que as dietas utilizadas no experimento não influenciaram no ciclo de mudas das lagostas.

Observa-se, contudo, que são poucos os trabalhos relacionados à frequência de mudas em lagostas. Acrescente-se que os existentes abordam a influência da ablação do pedúnculo ocular no ciclo de mudas nas lagostas (KOBAYASHI, 1998). Sabe-se, além disso, que o ciclo de muda é um dos fatores mais importantes de serem avaliados, pois se trata de parâmetro diretamente interligado à taxa de crescimento nos crustáceos, bem como ao ganho em comprimento, peso e biomassa final.

As taxas de sobrevivência observada nos tratamentos testados foram bastante próximas entre si. Constatou-se não existir diferença estatística significativa pelo teste do Qui-quadrado de Pearson $(P>$ 0,05) (Figura 4).

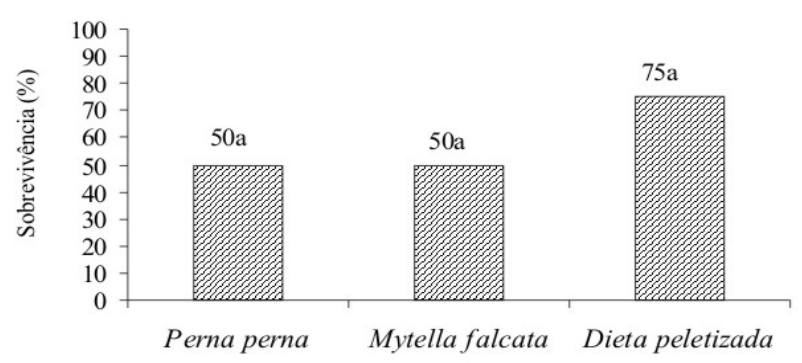

FIGURA 4. Taxas de sobrevivências (\%) da lagosta espinhosa Panulirus laevicauda, durante os 122 dias de cultivo, alimentadas com os moluscos Perna perna, Mytella falcata e dieta peletizada, em laboratório. Letras iguais não diferem entre si estatisticamente $(P>0,05)$.

SMITH et al. (2005) observaram que as lagostas da espécie $P$. ornatus, quando alimentadas com dietas peletizadas, apresentaram taxas de sobrevivência de 79\%. BARCLAY et al. (2006), utilizando mexilhões (M. edulis e $P$. canadiculus) e dieta peletizada na alimentação da $P$. ornatus, obtiveram taxas de sobrevivência de $95 \%$ para os indivíduos alimentados 
com a dieta peletizada, $94 \%$ e $70 \%$ para as lagostas alimentadas com os moluscos M. edulis e P. canadiculus, respectivamente.

Os resultados encontrados neste trabalho estão de acordo com os relatados por SMITH et al. (2005) e BARCLAY et al. (2006).

No que se refere às análises bromatológicas dos alimentos, verificou-se que os alimentos naturais compostos pelos moluscos P. perna e M. falcata apresentaram níveis bastante próximos de proteína total, lipídeos totais e carboidratos (Tabela 1). Porém, quando comparados com a dieta peletizada, observou-se que esta apresentou níveis bem mais altos de proteína total, lipídeos totais e carboidratos.

Estudos sobre a fisiologia digestiva de juvenis e adultos de lagostas atestam sua preferência alimentar carnívora com alta atividade proteolítica (tripsina, quimiotripsina e carboxipeptidase A), moderada carbohidrase ( $\alpha$-amilase, $\beta$-glucosaminidase, laminarinase e cellobiase) e uma relativa baixa na atividade da lipase (BARKAI et al., 1996; JOHNSTON \& YELLOWLEES, 1998; JOHNSTON, 2003; CELIS-GUERRERO et al., 2004).

Segundo GLENCROSS et al. (2001), P. cygnus obtiveram melhor crescimento quando alimentados com rações contendo $55 \%$ de proteína bruta, com baixos níveis de lipídeos. SMITH et al. (2003) citaram que $P$. ornatus apresentaram ótimo crescimento com dietas contendo entre $47 \%$ e $53 \%$ de PB e níveis de lipídeos de 6\% a 10\%. JOHNSTON (2003) relatou que a razão ótima entre carboidratos e lipídeos para juvenis de J. edwardsii é de 2:1. Também foi observado que crustáceos preferem dietas contendo no máximo $10 \%$ de lipídeos. Porém, níveis mais altos causam uma depressão no crescimento.

Esses resultados sugerem que as espécies de lagostas têm diferentes necessidades dietéticas de proteínas e lipídeos e, portanto, podem exigir alimentos dirigidos especificamente para cada espécie (WILLIAMS, 2007).

Segundo IGARASHI (2007), o cultivo de lagostas com qualquer tipo de alimento natural durante todo o período de cultivo, provavelmente, não é sustentável e nem lucrativo economicamente, razão pela qual é necessário realizar mais pesquisas, visando conhecer melhor o comportamento alimentar, crescimento, os requerimentos nutricionais e a fisiologia digestiva das espécies de lagostas. WILLIAMS (2007) relatou também que a falta de conhecimentos das necessidades nutricionais particulares das espécies de lagostas espinhosas é uma das principais razões para mais estudos.

\section{CONCLUSÕES}

A aceitação e a utilização de dieta peletizada na alimentação da lagosta espinhosa $P$. laevicauda são tidas como uma promissora ferramenta para o desenvolvimento de juvenis recentes em cativeiro. No que concerne aos moluscos P. perna e M. falcata, estes se apresentam como grandes candidatos a serem utilizados na alimentação de juvenis recentes de lagostas espinhosas. Uma combinação de alimentos naturais frescos compostos por mexilhões e uma dieta peletizada na alimentação das lagostas poderão, porém, resultar melhores taxas de crescimento e sobrevivência.

\section{AGRADECIMENTOS}

À Coordenação de Aperfeiçoamento do Pessoal do Nível Superior (CAPES), pela Bolsa de Mestrado concedida ao primeiro autor nos anos de 2005 a 2006.

\section{REFERÊNCIAS}

AOAC. Methods of analyses of the association of official analytical chemist's. Virginia. $15^{\text {th }}$ ed. Virginia: AOAC, 1990. 1298 p.

ARAGÃO, L. C. Efeitos das diferentes dietas naturais no desenvolvimento de juvenis de lagosta espinhosa Panulirus argus (Latreiile, 1804), em laboratório. 2005. 67 f. Dissertação (Mestrado em Engenharia de Pesca) - Departamento de Engenharia de Pesca, Universidade Federal do Ceará, Fortaleza, Ceará, 2005.

AYRES, M.; AYRES JUNIOR, M.; AYRES, D. L.; SANTOS, A. D. S. BioEstat 4.0: aplicações estatísticas nas Áreas das Ciências Biomédicas. Belém: Imprensa Oficial do Estado do Pará, 2005. 334 p. 1 CD.

BARCLAY, M. C.; IRVIN, S. J.; WILLIAMS, K. C.; SMITH, D. M. Comparison of diets for the tropical spiny lobster Panulirus ornatus: astaxanthin-supplement feed and mussel flesh. Aquaculture Nutrition, v. 12, p. 117-125, 2006.

BARKAI, A.; DAVIS, C. L.; TUGWELL, S. Prey selection by the South African cape rock lobster Jasus lalandii: ecological and 
physiological approaches. Bulletin of Marine Science, v. 58, p. $1-8,1996$

BOOTH, J. D.; KITTAKA, J. Spiny lobster growout. In: PHILLIPS, B. F.; KITTAKA, J. (Ed.). Spiny lobster: fisheries and culture. Oxford: Fishing News Books. 2. ed. 2000. p. 556-585.

BROWSER, P. R.; ROSEMARK, R. Mortalities of cultured lobsters, Homarus, associated with a molt death syndrome. Aquaculture, v. 23, p. 11-18, 1981.

CELIS-GUERRERO, L. E.; GARCIA-CARRERO, F. L.; DEL TORO, A. N. Characterization of proteases in the digestive system of spiny lobster (Panulirus interruptus). Marine Biotechnology, v. 6, p. 262-269. 2004.

CONCEIÇÃO, R. N. L. Biometria, genética-bioquímica e ecofisiologia de pós-larvas e juvenis da lagosta Panulirus argus (Latreille, 1804) (Crustacea, Decapoda). 1993. 108 f. Dissertação (Mestrado em Biologia Marinha) - Faculdade de Biologia, Centro de Investigaciones Marinas, Universidade de La Habana, La Habana, Cuba, 1993.

CREAR, B. J.; THOMAS, C. W.; HART, P. R.; CARTER, C. G. Growth of juvenile Southern rock lobsters, Jasus edwardsii, is influenced by diet and temperature, whilst survival is influenced by diet and tank environment. Aquaculture, v. 8, p. 169-182, 2000.

DÍAZ-IGLESIAS, E.; BRITO, R. P.; BAEZ-HIDALGO, M. Cria de postlarvas de langosta Panulirus argus em condiciones de laboratorio. Revista de Investigaciones Marinas, v. 12, n. 1/3, p. 323-331, 1991.

ESTEVES, F. A. Fundamentos de limnologia. São Paulo: Interciência FINEP, 1998. 575 p.

GLENCROSS, B. SMITH, M.; CURNOW, J.; SMITH, D.; WILLIAMS, K. The dietary protein and lipid requirements of postpuerulus western rock lobster, Panulirus cygnus. Aquaculture, v. 199, p. 119-129, 2001.

IGARASHI, M. A. Nota técnica sobre o desenvolvimento de juvenis recentes de lagosta Panulirus laevicauda até o tamanho comercial. Boletim Técnico Cientifico do CEPENE, v. 8, n. 1, p. 297-301, 2000.

IGARASHI, M. A. Sinopse da situação atual, perspectivas e condições de cultivo para lagostas Palinuridae. Ciência Animal Brasileira, v. 8, n. 2, p. 151-166, 2007.

IGARASHI, M. A.; KOBAYASHI, R. K. Desenvolvimento de lagosta Panulirus argus de puerulus ao tamanho comercial. Boletim Técnico Científico do CEPENE, v. 5, n. 1, p. 147-151, 1997.

IGARASHI, M. A.; MAGALHÃES NETO, E. O. Estratégia para o desenvolvimento da aquicultura no Nordeste brasileiro. Revista Econômica do Nordeste, v. 32, n. 2, p. 148-165, abr.-jun. 2001.

IGARASHI, M. A.; SANTOS, C. H. A. Ocorrência de fêmea ovígera de lagosta espinhosa Panulirus laevicauda em laboratório.
In: SIMPÓSIO BRASILEIRO DE AQUICULTURA, 11., 2000, Florianópolis, Anais... Florianópolis: AEP-SUL, 2000. 1 CD.

INSTITUTO ADOLFO LUTZ. Normas analíticas do Instituto Adolfo Lutz: métodos químicos e físicos para análise de alimentos. São Paulo: Instituto Adolfo Lutz, 1985. v. 1, p. 188-205.

JOHNSTON, D. J. Ontogenetic changes in digestive enzyme activity of the spiny lobster, Jasus edwardsii (Decapoda; Palinuridae). Marine Biological, v. 143, p. 1071-1082, 2003.

JOHNSTON, D. J.; YELLOWLEES, D. Relationship between dietary preferences and digestive enzyme complement of the slipper lobster Thenus orientalis (Decapoda Parastacidae). Journal of Crustacean Biology, v. 18, p. 656-665, 1998.

KITTAKA, J. Culture of larval spiny lobsters. In: PHILLIPS, B. F.; KITTAKA, J. (Ed.). Spiny lobster: fisheries and culture. 2. ed., Oxford: Fishing News Book, 2000. p. 508-592.

KITTAKA, J.; BOOTH, J. D. Prospectus for aquaculture. In: PHILLIPS, B. F.; KITTAKA, J. (Ed.). Spiny lobster: fisheries and culture. 2. ed. Oxford: Fishing News Book, 2000. p. 465-473.

KOBAYASHI, R. K. Efeitos da ablação unilateral do pedúnculo ocular, no desenvolvimento de juvenis de lagosta espinhosa Panulirus argus, submetidos a diferentes dietas. 1998. $91 \mathrm{f}$. Dissertação (Mestrado em Engenharia de Pesca) - Departamento de Engenharia de Pesca, Universidade Federal do Ceará, Fortaleza, Ceará, 1998.

LELLIS, W. A. A standard reference diet for crustacean nutrition research VI. Response of postlarval stages of the Caribbean king crab Mithrax spinosissimus and the spiny lobster Panulirus argus Journal of the World Aquaculture Society, v. 3, n. 1, p. 1-7, 1992.

MENDES, P. P. Estatística aplicada à aquicultura. Recife: Editora Bagaço, 1999. 265 p.

SANTOS, F. C. V. Cultivo de camarão marinho Litopenaeus vannamei (Boone, 1931), alimentado com rejeito de pesca. 2000. 22 f. Monografia (Bacharel em Engenharia de Pesca) Departamento de Engenharia de Pesca, Universidade Federal do Ceará, Fortaleza, Ceará, 2000.

SANTOS, C. H. A.; GALDINO, J. W.; IGARASHI, M. A. Efeito da ablação do pedúnculo ocular no cultivo de juvenis de lagostas espinhosas Panulirus laevicauda (Latreille, 1817) cultivadas sem a renovação da água do cultivo. In: CONGRESSO BRASILEIRO DE ENGENHARIA DE PESCA, 13., 2003. Porto Seguro. Anais... Porto Seguro: AEP-BA/FAEP-BR, 2003. p. 265-273. 1 CD.

SANTOS, C. H. A. Engorda de juvenis recentes da lagosta espinhosa Panulirus laevicauda (Latreille, 1817) alimentados com ração comercial para camarão marinho e os moluscos Mytella falcata e Perna perna, em condições de laboratório. 2006. 101f. Dissertação (Mestrado em Engenharia de Pesca) Departamento de Engenharia de Pesca, Universidade Federal do Ceará, Fortaleza, Ceará, 2006. 
SMITH, D. M.; WILLIAMS, K. C.; IRVIN, S. J. Response of the tropical spiny lobster Panulirus ornatus to protein content of pelleted feed and to a diet of mussel fresh. Aquaculture Nutrition, v. 11, p. 209-217, 2005.

SMITH, D. M.; WILLIAMS, K. C.; IRVIN, S. J.; BARCLAY, M.; TABRETT, S. Development of a pelleted feed for juvenile tropical spiny lobster (Panulirus ornatus): response to dietary protein and lipid. Aquaculture Nutrition, v. 9, p. 231-237, 2003.

WIEGAND, M. C. Observações sobre o desenvolvimento de juvenis de lagosta, Panulirus argus (Latreille, 1904), em laboratório, sob diferentes salinidades. $2005.37 \mathrm{f}$. Monografia
(Bacharel em Engenharia de Pesca) - Departamento de Engenharia de Pesca, Universidade Federal do Ceará, Fortaleza, Ceará, 2005.

WIEGAND, M. C.; LOURENÇO, J. A.; SANTOS, C. H. A.; IGARASHI, M. A. Observações sobre a utilização de diferentes dietas no desenvolvimento de juvenis recentes da lagosta espinhosa Panulirus argus (Latreille, 1804) em laboratório. In: ENCONTRO DE PESQUISA E PÓS-GRADUAÇÃO DO CEFETCE, 6., 2006. Fortaleza. Anais... Fortaleza: CEFETCE, 2006, 1 CD.

WILLIAMS, K. C. Nutritional requerements and feeds development for post-larval spiny lobster: a review. Aquaculture, v. 263, p. $1-14,2007$.

Protocolado em: 29 mar. 2007. Aceito em: 3 nov. 2009. 